\title{
JEANine TOLEdo
}

\section{Ana Cármen Palhares}

Jeanine de Lima Toledo, nascida em Maceió, Alagoas, 1962, muda-se para a cidade do Recife em finais dos anos de 1970. Ao longo das décadas seguintes, a artista desenvolve sua carreira naquela cidade, de onde ganhou projeção nacional e acumulou premiações e participações em Salões de Arte e Exposições coletivas e individuais. $\mathrm{Na}$ última década, entretanto, migrou para a cidade do Rio de Janeiro, onde manteve a sua pesquisa e atuação artística.

Jeanine Toledo atua muito fortemente com a pintura e por meio dela ultrapassa os limites da tela e faz do corpo também suporte.

A leveza do traço desvela a pele nua onde as referências artísticas são registradas em nomes e poses. Cézanne, Goya, Duchamp, Picasso, Bourgeois, Ingres, Sherman, Coubert, Bispo, Kahlo... São tantas e tão belas as influências que compõem a 'árvore genealógica' da artista e tornam suas obras universais.

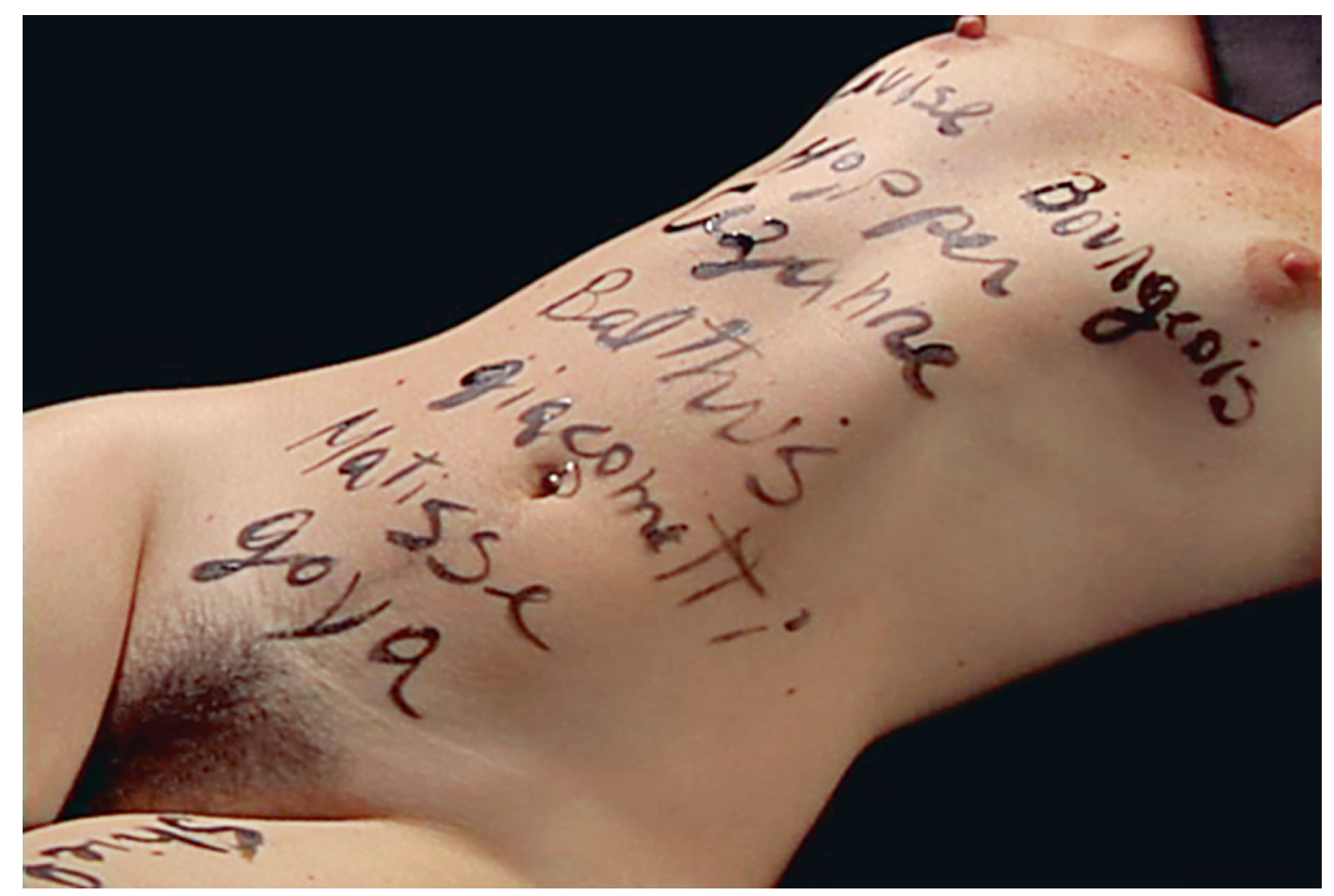

Figura 1: Frame do vídeo: Uns e Outros, Jeanine Toledo, 2003'

\footnotetext{
' Retirado de http://www.jeaninetoledo.com.br/corpor.html
} 

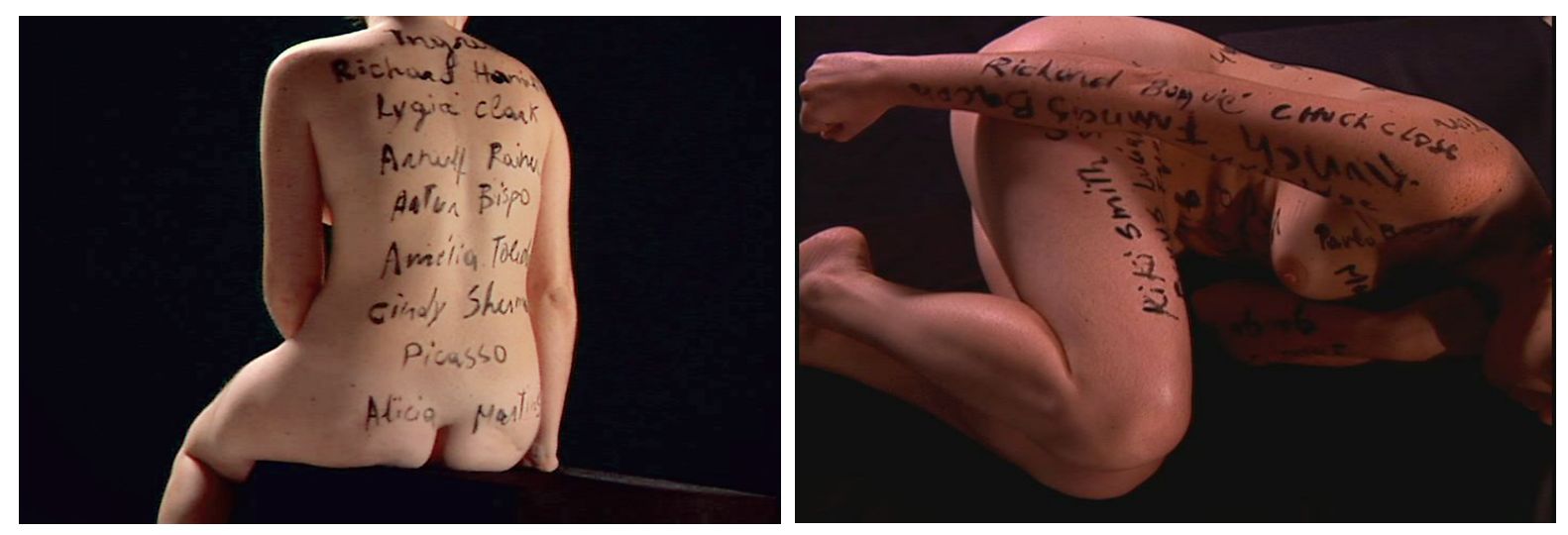

Figura 2: Frames do vídeo: Uns e Outros, Jeanine Toledo, $2003^{2}$

A mulher, tema recorrente em grande parte da obra de Jeanine Toledo (Figuras 1 e 2), é referência e suporte, é cor e leveza, protagonista e modelo. Essa artista incansável na busca de suas representações é minuciosa, exigente, perfeccionista. Ela nos traz não apenas releituras de obras-mestras, ela as reescreve com suas próprias cores e palavras.

Em "Gênesis" (Figura 3), a artista usa a força do pincel e tinge de vermelho e em grandes dimensões L'Origine Du Monde3, expondo não apenas um ícone mas um objeto de pesquisa e inquietação.

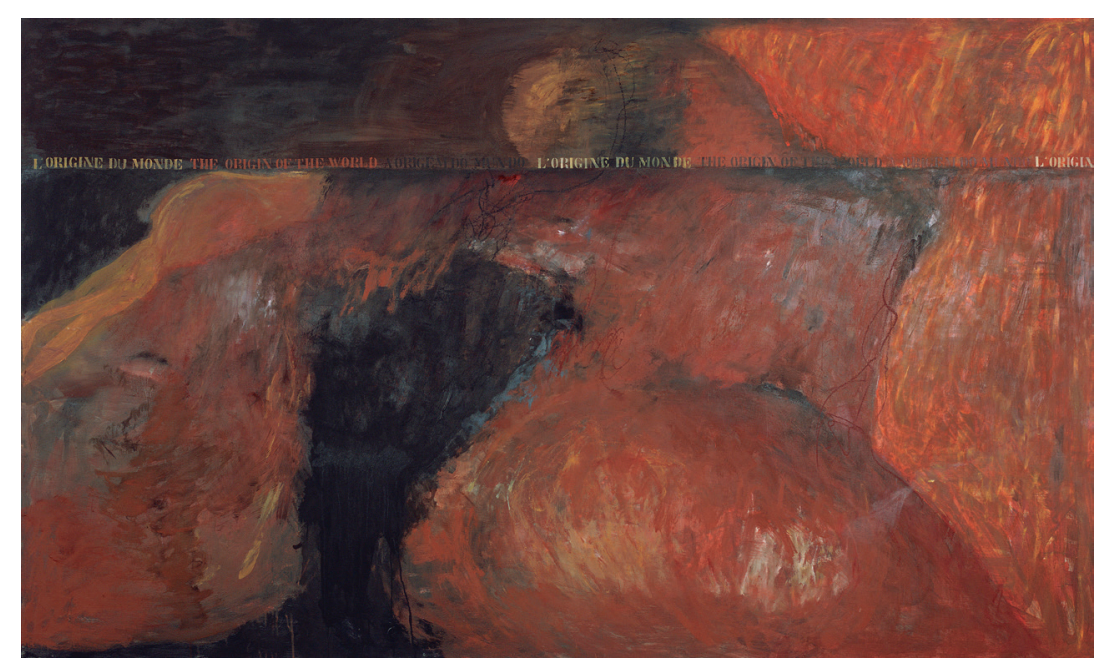

Figura 3: "Cênesis", Jeanine Toledo, 2003 - Óleo sobre tela | 160 x 270 cm

Se existe na arte um espaço para o indivíduo ultrapassar seus próprios limites, Jeanine Toledo o faz em cores e vibrações.

\footnotetext{
${ }^{2}$ Retirado de http://www.jeaninetoledo.com.br/corpor.html

3 Referência à obra de Gustave Coubert, 1866.

${ }_{4}$ Retirado de http://www.jeaninetoledo.com.br/corpol.html
} 


\section{REFERÊNCIAS BIBLIOGRÁFICAS}

Toledo, J. (2003). Uns e outros. Retirado de http://www.jeaninetoledo.com.br/corpor.html

Toledo, J. (2003). "Gênesis". Retirado de http://www.jeaninetoledo.com.br/corpoi.html

\section{NotA BIOGRÁFICA}

Ana Cármen Palhares é estudante do doutoramento de Estudos Culturais da Universidade do Minho e Universidade de Aveiro e membro do Centro de Estudos de Comunicação e Sociedade.

E-mail: anacarmenpalhares@gmail.com

Centro de Estudos de Comunicação e Sociedade, Instituto de Ciências Sociais, Campus de Gualtar, 4710-057 Braga, Portugal

* Submetido: 28/03/2017

* Aceite: $01 / 05 / 2017$ 